\title{
Secondary retinitis pigmentosa and cerebral demyelination in Lyme borreliosis
}

\author{
Anni Karma, Tuula A Pirttilä, Matti K Viljanen, Yrjö E Lähde, Christina M Raitta
}

Finland

T A Pirttilä

Tampere University, Department of Ophthalmology, Tampere, Finland

Y E K Lähde

Correspondence to: Dr Anni Karma, Department of Ophthalmology, University of Helsinki, SF-00290 Helsinki, Finland.

Accepted for publication 15 September 1992

Figure 1 Angiogram of the left fundus (late phase) demonstrating atrophy of the $R P E$ and possibly of the choriocapillaris and cystoid macular oedema.

Hyperfluorescence of the disc borders indicating

demyelination. Net-like retinal pigment aggregations in the periphery.

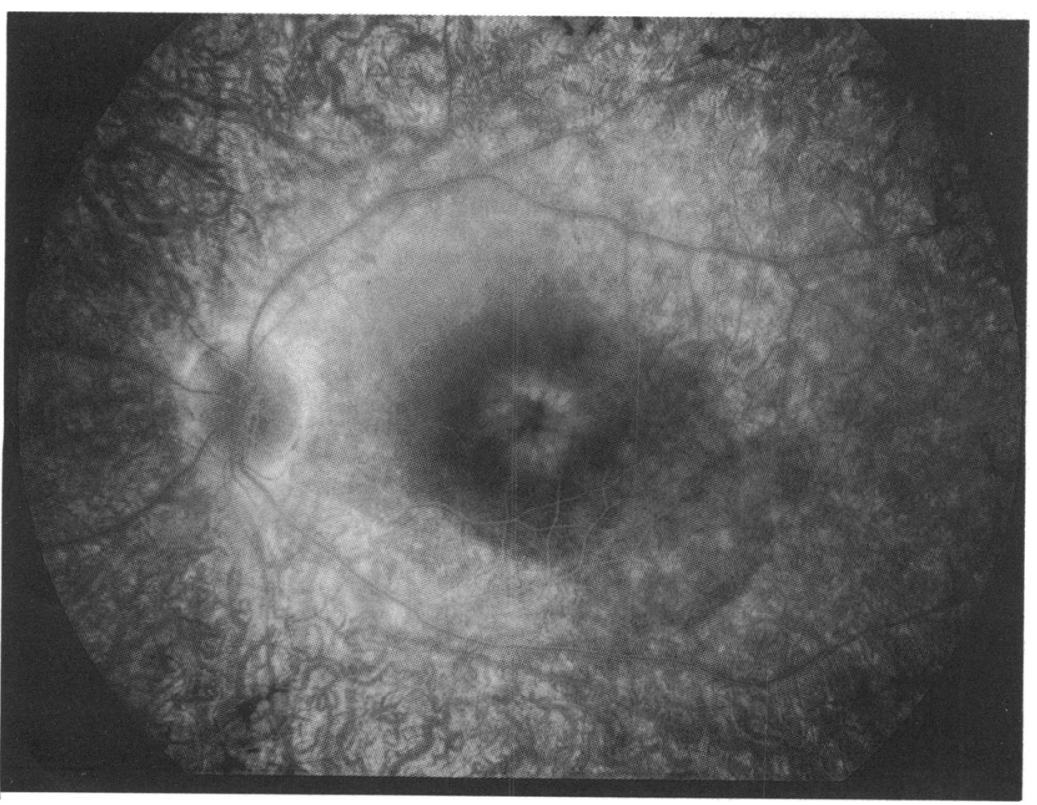

\begin{abstract}
Helsinki University, Department of Ophthalmology, Helsinki, Finland A Karma C M Raitta

National Public Health Institute, Turku, Finland M K Viljanen

Tampere University, Department of

Neurology, Tampere,

Abstract

A 15-year-old girl developed retinitis pigmentosa-like fundus changes in the left eye and optic neuropathy in the right eye as well as cerebral demyelination as a result of late Lyme borreliosis (LB). The diagnosis was confirmed by polymerase chain reaction, which detected a Borrelia burgdorferi specific segment of a gene coding for $41 \mathrm{kD}$ endoflagellin, both in the vitreous and the cerebrospinal fluid. The diagnosis was delayed because testing for Borrelia antibodies in serum and cerebrospinal fluid yielded negative results. However, later on, another laboratory reported the antibodies of the patient's pretreatment serum to be positive for $\mathbf{L B}$.
\end{abstract}

and cerebrospinal fluid (CSF) yielded negative
(Brf Ophthalmol 1993; 77: 120-122)

Lyme borreliosis (LB) is a complex multisystem disorder caused by a tick-borne spirochaete, Borrelia burgdorferi. Ophthalmic manifestations of the disease include external ocular and intraocular inflammations, retinal vasculitis, and optic neuropathy..$^{1-5}$ The diagnosis of ocular LB has usually been based on demonstration of elevated antibody titres to $B$ burgdorferi in serum. However, the results of the serological tests for LB may vary from one laboratory to another, ${ }^{6}$ which makes a proper diagnosis difficult.

We document a patient who presented with a retinitis pigmentosa (RP)-like clinical picture, with extinguished electroretinogram (ERG) in one eye and optic neuropathy in the other eye. The specific diagnosis was delayed because repeated testing for Borrelia antibodies in serum results. The diagnosis of Lyme borreliosis was finally confirmed by polymerase chain reaction (PCR). The PCR detected, both in the vitreous and CSF of the patient, a $B$ burgdorferi specific segment of a gene coding for $41 \mathrm{kD}$ endoflagellin.

\section{Case report}

A 15-year-old girl presented in January 1989 with a complaint of decreasing vision and constriction of the visual field in the left eye for several months. Eight months earlier she had experienced a flu-like illness with low grade fever and giddiness and transient hyperbilirubinaemia. She did not remember a tick bite or erythema chronicum migrans, but she had suffered from fluctuating unspecific eczema for years. Family history for hereditary eye diseases was unremarkable.

Visual acuity was $20 / 20$ in the right eye and $20 / 40$ in the left eye. Biomicroscopy revealed opacity of the posterior capsule and posterior vitritis in the left eye. Both optic discs were pale. The retinal pigment epithelium (RPE) of the left eye was very atrophic. A net-like corpuscular pigmentation in the equatorial retina and attenuation of arterioles resembling $\mathrm{RP}$ were seen. The RPE in the right fundus was also thinned but the retinal vessels were of normal calibre and no abnormal pigmentation was seen. A fluorescein angiogram of the left fundus revealed delayed retinal circulation and incomplete filling of the venules. Choroidal fluorescence was exaggerated from the initial phases and cystoid macular oedema in the late phases was demonstrated (Fig 1). In the right fundus an increased late choroidal fluorescence was seen (Fig 2). The left visual field was constricted to 15 degrees with a small intact temporal strip. An electroretinogram of the left eye was extinguished. Visual evoked responses of both eyes were delayed.

A chest $x$ ray disclosed no abnormalities. Complete blood cell count and sedimentation rate as well as liver enzymes were normal. Results of serological tests for human immunodeficiency virus; cytomegalovirus; Epstein-Barr, measles, and herpes simplex virus; Treponema pallidum; Toxoplasma, Toxocara; and Leptospira were unremarkable. IgM and IgG antibodies to $B$ burgdorferi (tested by enzyme linked immunosorbent assay (ELISA) in the Department of Biomedical Sciences, University of Tampere, Finland) were repeatedly negative (titre $<1: 100$, the cutoff point being 1:200). A CSF sample revealed $10 \times 10^{6} / 1$ lymphocytes and a high level oligoclonal IgG production, but Borrelia antibodies by ELISA were not found. Magnetic resonance imaging (MRI) of the brain in T2- 


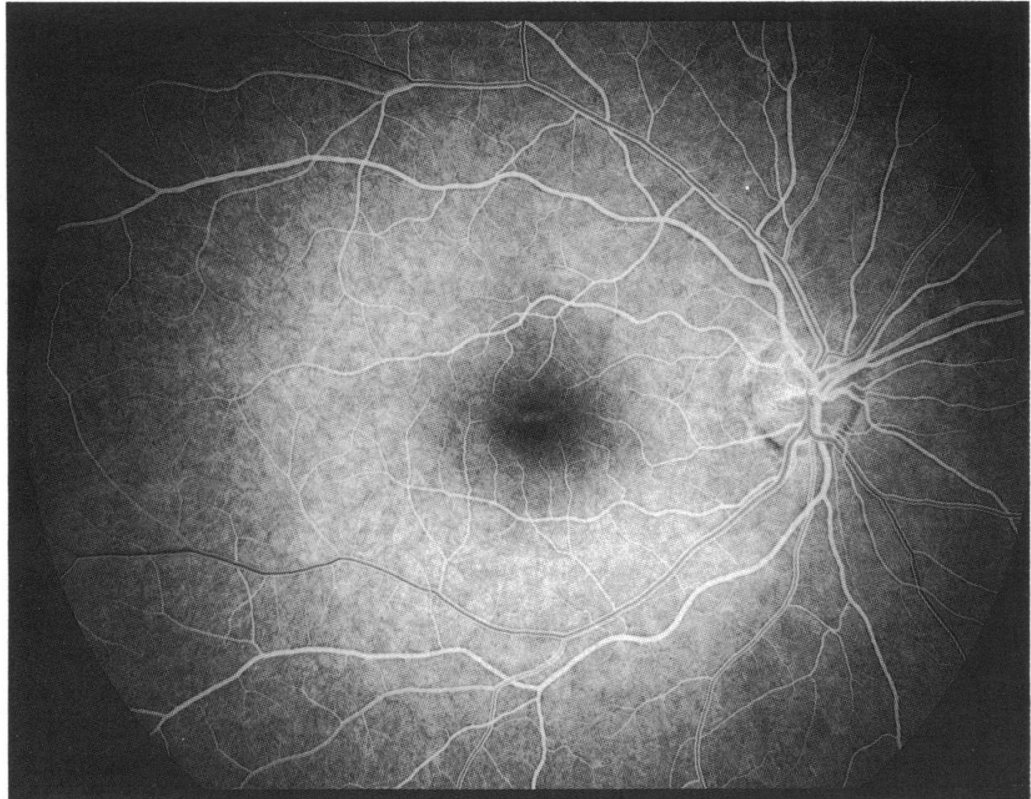

Figure 2 Angiogram(midvenous phase) of the right fundus showing choroidal hyperfluorescence and pigment defects of the macular area.

weighted images disclosed multiple hyperintensive white matter lesions periventricularly (Fig 3).
During the summer of 1990 ( 2 years after the first eye examination) the patient developed transient radicular pains on the left side of the body and left leg. Neurological investigation revealed missing achilles tendon reflexes and mild balance disturbance in a one foot standing test. Clinical neurological findings were compatible with multiple sclerosis. Intravenous methyl prednisolone therapy was initiated for 1 week and was followed by oral cyclosporine for 3 months. Visual acuity of both eyes decreased two lines. Reduced sensitivities appeared in the right computer visual field and left visual field constricted to a complete tunnel field.

CSF and vitreous fluid specimens were taken

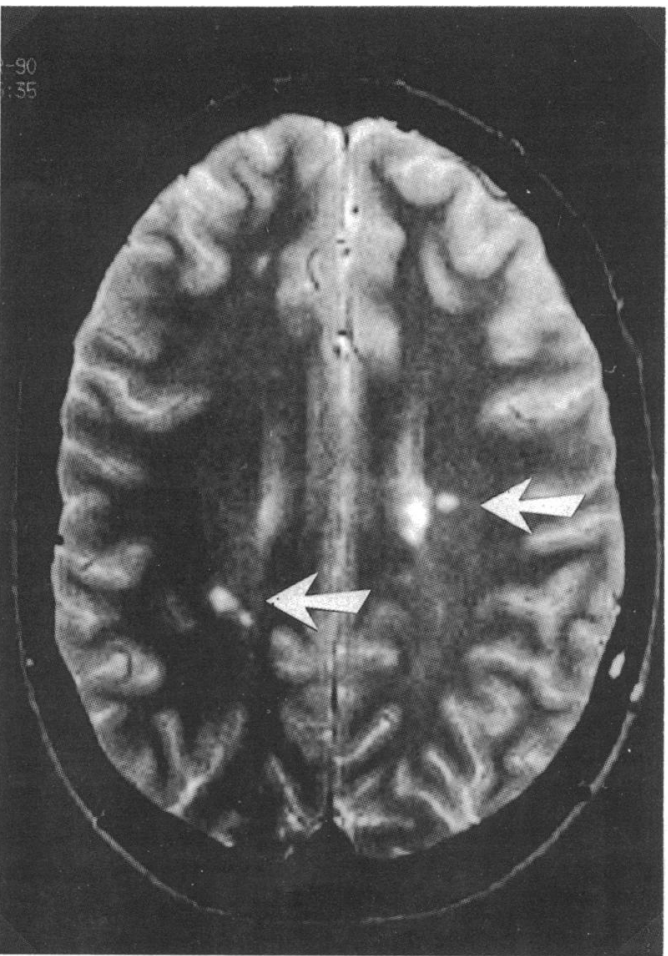

for PCR in May 1991. The PCR test (performed in the National Public Health Institute, Turku, Finland) which amplifies a segment of the gene coding for Borrelia endoflagellin, ${ }^{7}$ yielded a strong positive results from the CSF, and a weaker positive result from the vitreous.

The positive PCR results were confirmed by repeated testing of the specimens. A negative control assayed simultaneously with the specimens of the patient remained negative, thus excluding the possibility of contamination during the assay.

The patient received $2 \mathrm{~g} /$ day of intravenous ceftriaxone for 3 weeks, and $1 \mathrm{~g} /$ day of oral cefuroxime was subsequently administered for 1 month. In the follow-up examination 8 months later the visual functions were unchanged but the vitreal inflammation of the left eye had decreased. Symptoms of peripheral neuropathy and CSF pleocytosis had disappeared.

Later retesting the pretreatment serum sample in another laboratory (Department of Serology and Bacteriology, University of Helsinki, Finland) showed positive titres for LB by ELISA (IgG 1:1700, the cut off point being 1:500, and IgM 1:3000, the cut off point being 1:2000). A marked T-cell blastogenesis to $B$ burgdorferi was also shown in the patient's serum.

\section{Comment}

In our patient there was a strong correlation between pigmentary retinopathy, optic neuropathy, vitreal inflammation, cerebral demyelination, CSF pleocytosis, and positive Lyme PCR test from the vitreous and CSF. Worsening of the visual functions with immunosuppressive therapy and a positive response with antibiotics and, finally, a positive Lyme ELISA test further substantiated the diagnosis of neuro-ophthalmic LB.

The PCR method for amplification of a $B$ burgdorferi endoflagellin gene segment was crucial in the diagnosis of our patient. To date, having studied CSF specimens from about 100 patients with a suspicion of Lyme borreliosis we have found five positive results, including the present case. Further, we have tested numerous CSF specimens taken from patients with other infections and no positive reactions have been seen.

To our knowledge this is the first time the PCR method has been utilised in diagnosing vitreo-retino-choroidal late borreliosis. In our patient the vitreous and the CSF samples were negative in culture for Borrelia. It is possible that there were only a few spirochaetes left or no live organisms at all, only their sequestrated remnants.

Our patient presented with ophthalmic and ERG findings which resembled unilateral RP. However, signs of demyelination of both optic nerves, vitreous inflammation, and retinal oedema did not agree with hereditary pigment dystrophy. One may speculate that if the RPE had been the primary target for the spirochaetes and the defence mechanisms, the RPE cells owing to their phagocytic properties may have destroyed the living spirochaetes, leaving behind an atrophic sensory retina, RPE, and chorio- 
capillaris, as well as the remaining immunological response.

The ocular disease of our patient had a remarkable similarity to syphilitic neuroretinitis described by Duke-Elder as retinitis circumpapillaris. ${ }^{8}$ Smith $e t a l^{9}$ has proposed previously that rare unilateral RP may in fact often have represented seronegative syphilis. Since late syphilis is extremely rare in Finland, it is an unlikely cause of our patient's disease. On the other hand, LB is endemic in the southwest archipelago of Finland and the number of new cases is also increasing in the southern parts of the mainland, from where our patient came.

We agree with MacDonald ${ }^{10}$ and others ${ }^{611}$ about the fact that serological testing for LB is ambiguous. Furthermore, Isogai and coworkers recently found Borrelia antibodies in a significant number of patients with non-infectious uveitis entities. ${ }^{12}$ Our case stresses the need for sophisticated methods to detect borrelial structures within the eye. The high sensitivity and specificity of the PCR method makes it one of the most promising candidates among the technological inovations in the diagnosis of borrelial and other microbial infections.

The early diagnosis of ocular borreliosis is of utmost importance. Elimination of $B$ burgdorferi from the eye at the early stages of infection may prevent the development of irreversible damages and possibly also the triggering of the autoimmune process.

1 Baum J, Barza M, Weinstein P, Groden J, Aswad M. Bilateral keratitis as a manifestation of Lyme disease. Am $\mathcal{F}$ Ophthalmol 1988; 105: 75-7.

2 Winward KE Smith JL, Culbertson WW, Paris-Hamelin A. Ocular Lyme borreliosis. Am f Ophthalmol 1989; 108: 6517 .

3 Bialasiewicz AA, Huk W, Druschky KF, Naumann GOH. Borrelia burgdorferi-Infektion mit beidseitiger Neuritis nervi optici und intrazerebralen Demyelinisierungsherden. Klin Monatsbl A ugenheilkd 1989; 195: 91-4.

4 Smith JL, Winward KE, Nicholson DF, Albert DW. Retinal vasculitis in Lyme borreliosis. $\mathcal{F}$ Clin Neuro Ophthalmol 1991; 11 : 7-15.

5 Schechter SL. Lyme disease associated with optic neuropathy. $A m$ F Med 1986; 81: 143-5.

6 Hedberg CW, Osterholm MT, MacDonald KL, White KE. An interlaboratory study of antibody to Borrelia burgdorferi. An interlaboratory study of antib

7 Wallich R, Moter SE, Simon MM, Ebnet K, Heiberger A, Kramer MD. The Borrelia burgdorferi flagellum-associated 41-kilodalton antigen (flagellin) - molecular cloning, expression, and amplification of the gene. Infect Immun 1990; 58: 1711-9.

8 Duke-Elder S, Dobree JH. Diseases of the retina. In: DukeElder S, ed. System of ophthalmology, Vol X. London: Kimpton, 1967: 252-62.

9 Smith J-L, Singer JA, Moore MD Jr, Yobs AR. Seronegative ocular and neurosyphilis. Am $\mathcal{F}$ Ophthalmol 1965; 59: 75363.

10 MacDonald AB. Ambiguous serologies in active Lyme borreliosis. $\mathcal{F}$ Clin Neuro Ophthàlmol 1988; 8: 79-80.

11 Winward KE, Smith JL. Ocular disease in Caribbean patients with serologic evidence of Lyme borreliosis. $\mathcal{f}$ Clin Neuro Ophthalmol 1989; 9: 65-70

12 Isogai $\mathrm{E}$, Isogai $\mathrm{H}$, Kotake $\mathrm{S}$, Yoshikawa $\mathrm{K}$, Ichiishi $\mathrm{A}$, Kosaka S, et al. Detection of antibodies against Borrelia burgdorferi in patients with uveitis. Am $\mathcal{F}$ Ophthalmol 1991; 112: 23-30.

\title{
Two cases of coloboma associated with unbalanced translocations
}

\author{
Michael Goggin, Michael O'Keefe, Helen Hughes
}

\begin{abstract}
Two cases of coloboma are recorded, both secondary to previously unreported unbalanced translocations. These cases underline the association of chromosomal abnormalities and coloboma, particularly when accompanied by systemic abnormalities. They also highlight the importance of a full systemic assessment of coloboma patients and adequate genetic counselling for both patients and their families. (BrF Ophthalmol 1993; 77: 122-123)
\end{abstract}

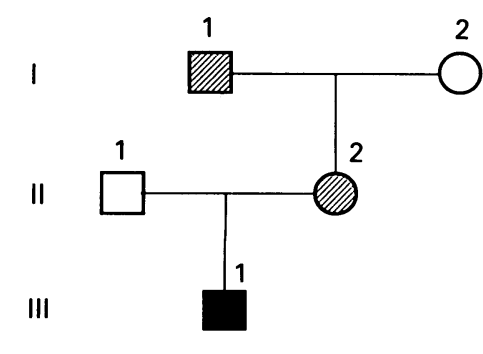

Family 1

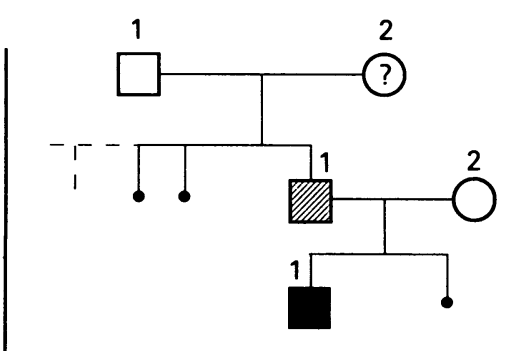

Family 2
Hereditary coloboma is described as an isolated defect often inherited as an autosomal dominant trait $^{12}$ and, less commonly, in an autosomal recessive manner. ${ }^{34}$ An $\mathrm{X}$-linked recessive pattern has also been described. ${ }^{5} \mathrm{It}$ is a feature of many syndromes, including various chromosomal disorders. These have been the subject of exhaustive reviews. ${ }^{26} \mathrm{We}$ report two patients with coloboma/microphthalmos related to unbalanced translocations not previously described in the literature.

\section{Case reports}

CASE 1

A male only child of a phenotypically normal father and mother presented at 4 months with bilateral severe ptosis occluding the visual axes (Fig 1, family 1, III-1). Both eyes were microphthalmic with colobomas of the iris, retina/choroid, macula, and disc. The child was also found to have a duplex renal system, cerebral atrophy, and developmental delay.

Bilateral frontalis sling ptosis procedures were carried out, and the fixation pattern has shown a steady improvement since then.

Chromosomal analysis revealed a 5-14 